\title{
Potentially Inappropriate Prescribing in Children
}

\author{
Emma Barry*, Susan M Smith \\ HRB Centre for Primary Care Research, Department of General Practice, Royal College of Surgeons in Ireland, Dublin, Ireland
}

\section{Article Info}

\section{Article Notes}

Received: August 14, 2018

Accepted: September 17, 2018

\section{${ }^{*}$ Correspondence:}

Dr. Emma Barry, HRB Centre for Primary Care Research, Department of General Practice, Royal College of Surgeons in Ireland, Dublin, Ireland; Telephone No: +3531-402-2144; Email: emmabarry@rcsi.ie.

(c) 2018 Barry $E$. This article is distributed under the terms of the Creative Commons Attribution 4.0 International License.

\section{Background}

There has been increasing focus on the quality of primary care for children with large scale population studies in the US and Australia reporting adherence to clinical guidelines of approximately 40 to $60 \%^{1,2}$. In particular, there is limited evidence on the safety and effectiveness of prescribing for children ${ }^{2}$. Medicines are generally considered appropriate in an adult population when they have a clear, evidence-based indication, are well tolerated in the majority of patients and are cost effective. Medicines or prescribing patterns that do not fit this description can be considered inappropriate or potentially inappropriate and may include misprescribing, over prescribing and underprescribing ${ }^{3}$. Potential consequences for children may be inadequate chronic disease management and unplanned hospital admissions and even rarely can result in preventable deaths ${ }^{4}$.

Optimal prescribing in children requires sufficient evidence on the safety and efficacy of medications in paediatric patients. However, studies show that for conditions with a high paediatric disease burden only a small proportion of clinical drug trials in these areas include paediatric patients ${ }^{5}$. Many drugs are unlicensed in children and are prescribed 'off label' and although not always inappropriate, the lack of a rigorous scientific basis for the prescription or dose can lead to side effects or adverse reactions. In 2007 the WHO launched a campaign to 'make medicines child size'. In an effort to address the issue of 'off label' prescribing, the European Medicines Agency and the US Food and Drug Administration now offer extensions to licenses to companies who provide evidence of safety and efficacy of a drug in a paediatric population. Current research highlights particular areas of concern for potentially inappropriate prescribing in asthma, antibiotics, anti histamines and amphetamines ${ }^{6}$.

\section{Prescribing Indicators}

The evaluation of whether medicines are prescribed rationally or appropriately is difficult. There has been insufficient research on developing validated tools to assess prescribing especially in children ${ }^{7}$. Prescribing indicators have been used to assess medication use in adult prescribing. Prescribing indicators or criteria can be defined as a measurable element of prescribing for which there is evidence or consensus that can be used to assess the quality of prescribing. Explicit prescribing indicators are specific statements of appropriateness of prescribing that are generally drug or diseases orientated and commonly focus on drugs to avoid. Drugs to avoid lists include medications that should be avoided in any circumstance, doses that should not be exceeded, and drugs that should be avoided 
in patients with specific conditions or disorders ${ }^{3}$. These criterion based tools can be applied to large prescription or dispensing databases with little or no clinical information available regarding diagnosis or investigations ${ }^{8}$. Although the evidence base for developing explicit prescribing indicators is limited, combining expert professional opinion with consensus methodology can create quality indicators in areas where it would not otherwise be possible ${ }^{9}$. Explicit indicators such as the Screening Tool of Older Persons Prescriptions (STOPP) criteria enable the identification of potentially inappropriate prescribing while the Screening Tool to Alert doctors to Right i.e appropriate Treatment (START) criteria can be used to identify potentially appropriate medications that have been omitted ${ }^{10}$. Version 2 of these criteria, developed in 2015, include 114 criteria 80 STOPP criteria and 34 START criteria ${ }^{10}$. Studies in older populations have been found the STOPP/ START criteria to be valid, reliable and generalizable across international primary care settings ${ }^{11}$. Studies have highlighted that explicit prescribing indicators are not sufficient to assess whether prescribing is appropriate or not in the context of assessing daily prescribing practices on an individual patient level ${ }^{12}$. However they can provide a means for comparing the prescribing practices of countries and can be used as outcomes to test whether interventions aimed at improving the safety and quality of prescribing have been effective ${ }^{13}$.

Ideally a prescribing indicator would be based on a thorough review of patient records with access to the full clinical and treatment history of the patient $t^{14}$, but this would be time consuming and could be extremely complex. A more realistic option is the development of prescribing quality indicators that can be applied to automated databases containing information on dispensed drugs. These databases are available in most developed countries; they generally lack detailed information about the patient or indication for the prescription but they allow process based prescribing indicators to be applied and to assess aspects of prescribing patterns, safety and cost effectiveness $^{15}$.

\section{Prescribing in Children with Asthma}

The management of paediatric asthma, which is the most common chronic condition in childhood has been identified as an area of concern in the literature as it continues to cause death in people of all ages despite a number of preventable factors ${ }^{16,17}$. Research in the UK has shown that adherence to international guidelines for example Scottish Intercollegiate Guidelines Network/ British Thoracic Society (SIGN/BTS) on pharmacological treatments is lacking in primary care ${ }^{18}$. European studies have also reported suboptimal treatment of asthma. In one Swedish study, $45 \%$ of children over seven years had at least one prescription of inhaled corticosteroids (ICS) and only $10 \%$ had more than four prescriptions over a two year period ${ }^{19}$. Studies of adherence to asthma guidelines in primary care in the US have also identified the failure to prescribe daily maintenance medication (e.g. leukotriene receptor antagonists and ICS) in up to one third of patients with persistent asthma ${ }^{20}$.In a previous study of Medicaid insured children with asthma in the USA, 73\% were under-users of controller therapy with $49 \%$ reporting no controller use and 24\% less than daily use $\mathrm{e}^{21}$.

Prescribing of a long acting beta agonist (LABA) without an ICS, referred to as LABA monotherapy, has been used as an indicator of the quality of asthma care in adults in a number of studies ${ }^{22,8}$. A recent Cochrane review found that LABA monotherapy in children was associated with an increased risk of serious non-fatal adverse events which were statistically significant for formoterol but not for salmeterol ${ }^{23}$. In clinical practice, ICS/LABA combination inhalers are widely prescribed reducing the risk of inadvertent prescribing of LABA monotherapy and these combination inhalers were not included in the PIPc indicator list. Low but persistent rates of LABA monotherapy have been found in European studies and UK studies $^{18,24}$.

The clinical significance of poor adherence to guidelines in asthma is highlighted in a US study in which an organized disease management program delivered to patients in primary care resulted in increased adherence to guidelines in addition to a $35 \%$ reduction in hospitalization rates, a 27\% decrease in Emergency department presentations and a $19 \%$ decrease in outpatient visits ${ }^{21}$. Barriers to physician adherence to guidelines identified in the literature include lack of awareness, familiarity and agreement with guidelines in addition to lack of self efficacy, lack of outcome expectancy and inertia of previous practice ${ }^{25}$.

\section{Antibiotic Prescribing}

A large multinational cohort study in primary care in 2010 found that the most commonly prescribed drugs in children are anti-infectives, dermatological agents and respiratory drugs. The prevalence of the most commonly prescribed drugs was highest in children under 2 years ${ }^{26}$. Many of these prescriptions may be inappropriate and it has been estimated that nearly $50 \%$ of antibiotic prescriptions for children given by primary care physicians are unnecessary ${ }^{27}$. For example, in the UK there are around six million antibiotic prescriptions for children each year, the majority of which are for upper respiratory infections, most of which likely have a viral aetiology ${ }^{28}$. The large scale population study of quality of care in Australia identified the overuse of antibiotics in eczema, croup, otitis media and tonsillitis as areas of concern with the use of antibiotics in tonsillitis as the only indicator with an estimated adherence of less than $50 \%{ }^{1}$. Inappropriate prescribing of antibiotics 
The following table presents the agreed PIPc Indicators:

Table 1. PIPc Indicators by system.

\begin{tabular}{|r|l|}
\hline 1 & Intranasal beclometasone should not be prescribed to children under 6 years \\
\hline 2 & Carbocsteine should not be prescribed to children \\
\hline 3 & An inhaled short acting beta-2 agonist should be prescribed to all children who are prescribed two or more inhaled corticosteroids \\
\hline 4 & $\begin{array}{l}\text { An inhaled short acting beta-2 agonist should be prescribed to children under } 5 \text { years who are prescribed a leukotriene receptor } \\
\text { antagonist }\end{array}$ \\
\hline 5 & An inhaled corticosteroid should be prescribed to children aged 5-15 years who are prescribed a long acting beta-2 agonist \\
\hline 6 & $\begin{array}{l}\text { Children under } 12 \text { years who are prescribed a pressurised metered-dose inhaler should also be prescribed a spacer device at least } \\
\text { every } 12 \text { months }\end{array}$ \\
\hline & Gastrointestinal System \\
\hline 7 & Loperamide should not be used in the treatment of diarrhoea in children under 4 years. \\
\hline 8 & Domperidone should not be prescribed concomitantly with erythromycin \\
\hline & Dermatological System \\
\hline 9 & Children prescribed greater than one topical corticosteroid in a year should also be prescribed an emollient \\
\hline 10 & Tetracyclines should not be prescribed to children under 12 years \\
\hline & Neurological System \\
\hline 11 & Codeine/Dihydrocodeine medications should not be prescribed to children under 12 years \\
\hline 12 & Sedating antihistamines should not be prescribed to children under 2 years \\
\hline
\end{tabular}

is, in turn, linked to increasing antibiotic resistance at both a population and individual level. A systematic review and meta-analysis, which included 11 studies on children, found that individuals prescribed an antibiotic in primary care for a respiratory or urinary infection developed bacterial resistance to that antibiotic and that this effect is greatest in the month immediately after treatment but may persist for up to 12 months ${ }^{29}$. The authors concluded that this effect not only increases the population carriage of organisms resistant to first-line antibiotics but also creates the conditions for increased use of second line antibiotics in the community ${ }^{29}$. On a positive note, a more recent study from the US of over 38,000 children has demonstrated a reduction in antibiotic use in children and adolescents from $8.4 \%$ to $4.5 \%$ from $1999 / 2002$ to $2011 / 14$ with the largest decrease in children under 2 years ${ }^{30}$.

\section{Measuring PIP in Children}

We developed a set of 12 prescribing indicators using a Delphi consensus methodology to support prescribing for children in primary care $^{31}$. The Delphi consensus method allowed an estimate of an overall group opinion to be reached by improving agreement between a panel of international experts through two rounds of an on-line questionnaire. The PIPc indicators developed related to commonly prescribed medications in Ireland and focused on indicators that could be applied in the absence of clinical information.

We are currently working on the application of these indicators to a primary care dispensing database to identify the prevalence of potentially inappropriate prescribing in children in primary care in Ireland.

\section{Conclusion}

The identification and measurement of potentially inappropriate prescribing in children remains a difficult and challenging task. Overall trends in prescribing rates are showing a slight reduction in the prescribing of some medications such as antibiotics but not in others such as amphetamines. Adherence to clinical guidelines by prescribing doctors could be improved, particularly for common chronic conditions like asthma. More research is required to provide clarity on the appropriateness and safety of prescribing in children.

\section{References}

1. Braithwaite J, Hibbert PD, Jaffe A, et al. Quality of healthcare for children in Australia, 2012- 2013. JAMA. 2018; 319(11): 1113-1124.

2. Mangione-Smith R, DeCristofaro AH, Setodji CM, et al. The quality of ambulatory care delivered to children in the United States. N Engl J Med. 2007; 357(15): 1515-23.

3. Spinewine A, Schmader KE, Barber N, et al. Appropriate prescribing in elderly people: how well can it be measured and optimised. Lancet. 2007; 370(9582): 173-84

4. Gill PJ, O'Neill B, Rose P, et al. Primary care quality indicators for children: measuring quality in UK general practice. Br J Gen Pract. 2014; 64(629): 752-7.

5. Bourgeois FT, Murthy S, Pinto C, et al. Paediatrics versus adult drug trials for conditions with high paediatric disease burden. Paediatrics. 2012; 130: 285 -92.

6. Freed GL. Medication Prescribing for Children: Progress and uncertainty. JAMA. 2018; 319(19): 1988-1989.

7. Choonara I. Rational prescribing is important in all settings. Arch Dis Child. 2013 Sep; 98(9): 720

8. Avery AJ, Dex GM, Mulvaney C, et al. Development of prescribingsafety indicators for GPs using the RAND Appropriateness Method. Br J Gen Prac. 2011; 61e526-536. 
9. Campbell SM, Cantrill JA. Consensus methods in prescribing research. J Clin Pharm Therap. 2001; 26: 5-14.

10. Gallagher P, Ryan C, Byrne S, et al. STOPP (Screening Tool of Older Person's Prescriptions) and START (Screening Tool to Alert doctors to Right Treatment). Consensus validation. Int J Clin Pharmacol Ther. 2008; 46: 72-83

11. O'Mahony D, O'Sullivan D, Byrne S, et al. STOPP/START criteria for potentially inappropriate prescribing in older people: version 2. Age Ageing. 2015 Mar; 44(2): 213-8

12. Dalleur O, Boland B, De Groot A, et al. Detection of potentially inappropriate prescribing in the very old: cross-sectional analysis of the data from the BELFRAIL observational cohort study. BMC Geriatr. 2015; 15: 156

13. Kaufmann CP, Tremp R, Hererger KE. Inappropriate prescribing, a systematic overview of published assessment tools. Eur J Clin Pharmacol. 2014 Jan; 70(1): 1-11.

14. Veninga CC, Denig P, Pont LG, et al. Comparison of indicators assessing the quality of drug prescribing for asthma. Health Serv Res. 2001; 36: 143-61

15. Andersen M. Is it possible to measure prescribing quality using only prescription data? Basic Clin Pharmacol Toxicol. 2006; 98: 314-9.

16. Asher I, Pearce N. Global burden of asthma among children. Int J Tuberc Lung Dis. 2014; 18(11): 1269-1278.

17. Bush A. Improving treatment of asthma attacks in children. BMJ. 2017; 359: 5763.

18. Thomas M, Murray-Thomas T, Fan T et al. Prescribing patterns of asthma controller therapy for children in UK primary care: a crosssectional observational study. BMC Pul Med. 2010; 10: 29.

19. Ingemansson M, Wettermark B, Jonsson EW, et al. Adherence to guidelines for drug treatment of asthma in children: potential for improvement in Swedish primary care. Qual Prim Care. 2012; 20(2): $131-9$.

20. Yawn BP, Rank MA, Cabana MD, et al. Adherence to Asthma Guidelines in Children, Tweens, and Adults in Primary Care Settings: A Practice-Based Network Assessment. Mayo Clinic proceedings. 2016; 91(4): 411-21.
21. Cloutier MM, Hall CB, Wakefield DB, et al. Use of asthma guidelines by primary care providers to reduce hospitalizations and emergency department visits in poor, minority, urban children. J Pediatr. 2005; 146(5): 591-7.

22. Fernandez Urrusuno R, Montero Balosa MC, Perez Perez P,et al Compliance with quality prescribing indicators in terms of their relationship to financial incentives. Eur J Clin Pharmacol. 2013; 69(10): 1845-53.

23. Cates CJ, Welsh EJ, Rowe BH. Holding chambers (spacers) versus nebulisers for beta-agonist treatment of acute asthma. Cochrane Database Syst Rev. 2013; 9: CD000052.

24. Elkout H, Helms PJ, Simpson CR, et al. Changes in primary care prescribing patterns for paediatric asthma: a prescribing database analysis. Arch Dis Child. 2012; 97(6): 521-5.

25. Cabana MD, Ebel BE, Cooper-Patrick L, et al. Barriers paediatricians face when using asthma practice guidelines. Arch Pediatr Adolesc Med. 2000; 154(7): 685-93.

26. Stukenboom M. Drug use in children: cohort study in three European countries. BMJ. 2008; (337): 2245.

27. Pichichero ME . Dynamics of antibiotic prescribing for children JAMA. 2002; 287: 3133-5.

28. Harnden A, Perera R, Brueggemann AB, et al. Respiratory infections for which general practitioners consider prescribing an antibiotic: a prospective study. Arch Dis Child. 2007; 92: 594-7.

29. Costelloe C, Metcalfe C, Lovering A, et al. Effect of antibiotic prescribing in primary care on antimicrobial resistance in individual patients: systematic review and meta-analysis. BMJ. 2010; 340: 2096.

30. Hales CM, Kit BK, Quiping G et al. Trends in prescription medication use among children and adolescents-United States, 1999-2014. JAMA. 2018; 319(19): 2009-2020.

31. Barry E, O'Brien K, Moriarty F, et al. PIPc study: development of indicators of potentially in appropriate prescribing in children (PIPc) in primary care using a modified Delphi technique. BMJopen. 2016; 6(9): 012079. 